\title{
O EFEITO DA COMPLEXIDADE E DA COERÊNCIA DEESCRITÓRIOS DE COWORKING NA QUALIDADE VISUAL PERCEBIDA
}

\author{
OLIVEIRA, Cassandra Kopinits (1); \\ COSTA FILHO, Lourival (2) \\ (1) UFPE | PPGDesign, Mestranda em Design \\ e-mail: cakopinits@gmail.com \\ (2) UFPE | PPGDesign, Doutor em Desenvolvimento Urbano \\ e-mail: lourivalcosta@yahoo.com
}

\begin{abstract}
RESUMO
Este artigo objetiva prover informações empíricas sobre o efeito da complexidade e da coerência de escritórios de coworking na qualidade visual percebida. Para tal, uma sentença mapeadora geral, instrumento básico da Teoria das Facetas, foi adotada no desenho da investigação empírica, que optou por um questionário online para coletar dados e pela tabela de distribuição das frequências para avaliá-los. Os achados revelaram apenas parcialmente os efeitos da complexidade e da coerência postulados para a qualidade visual percebida.
\end{abstract}

Palavras-chave: coworking, qualidade visual percebida, ergonomia do ambiente construído.

\begin{abstract}
This paper aims to provide empirical information on the effect of coworking offices' complexity and coherence on perceived visual quality. A general mapping sentence, a basic tool of Facet Theory, was therefore adopted in the design of the empirical investigation, which employed online questionnaire to collect the data and the frequency distribution table to evaluate the results. The findings only partially revelled the postulated effects of complexity and coherence on perceived visual quality.
\end{abstract}

Keywords: coworking, perceived visual quality, ergonomics of the built environment.

\section{INTRODUÇÃO}

Os projetos de espaços de trabalho, de uma maneira geral, passaram por importantes modificações desde as primeiras implantações, que obedeciam ao modelo taylorista-fordista de organização da produção, e vêm evoluindo. Uma evolução lenta, mas qualitativamente importante, graças ao desenvolvimento de ciências e tecnologias, que comprovam, a cada dia, a necessidade de projetos que garantam melhores condições de trabalho aos trabalhadores (REIS; MORAES, 2004).

Tais modificações, deram origem a novos tipos de uso e de usuário, que passaram a demandar complexas estruturas espaciais para abrigar igualmente complexas atividades de trabalho, como, por exemplo, aquelas observadas em escritórios de coworking, um novo modelo de trabalhar que se baseia no compartilhamento de espaço e recursos de escritório, reunindo profissionais liberais, empreendedores e usuários independentes que não necessariamente trabalham para a mesma empresa ou área de atuação. 
Esses espaços plurais de trabalho tornaram a compreensão das tarefas-atividades que neles acontecem, quem são, como agem os atores do processo de trabalho e como se dá o processo de trabalho, demasiadamente complexos de serem pré-determinados no processo de projeto, ou seja, de se atrelar essa compreensão do trabalho (tarefas-atividades) e do trabalhador (usuário) na função e na forma dos espaços.

As decisões de projeto, contudo, têm um efeito importante sobre as situações de trabalho, na medida em que o espaço resultante do projeto será a interface que permitirá as trocas e proporcionará a conformação do ambiente de trabalho, o que aponta para um enfoque nos domínios da ergonomia do ambiente construído.

A contribuição da ergonomia em projetos de espaços de trabalho busca a compreensão dos sistemas que compõem um ambiente organizacional para que, através dessa compreensão, os espaços de trabalho definidos permitam o desenvolvimento real das tarefas/atividades. Há também alguns cuidados específicos em relação aos trabalhadores (usuários), para que eles alcancem seus objetivos (realizem suas tarefas) dentro de boas condições.

Cabe ressaltar, apoiando-se em Reis e Moraes (2004), que o enfoque ergonômico ultrapassa dados antropométricos e ou biométricos, também importantes, mas deve também cumprir um entendimento maior sobre os trabalhadores em seu trabalho organizado. Dessa forma, os ambientes de trabalho relacionam-se também com fenômenos de ordem subjetiva que se identificam com elementos espaciais. Tais fenômenos interferem, interagem e atuam no desempenho do trabalhador, na realização de suas tarefas no ambiente de trabalho.

Ao tratar desse entendimento mais amplo do enfoque ergonômico, Van der Linden (2007) chama a atenção para que os fatores ergonômicos de projeto sejam atendidos a partir da perspectiva do ser humano, levando em consideração suas necessidades e seus desejos de uma forma que extrapole o racionalismo preconizado pela ergonomia tradicional. O autor ainda cita que realizar a descrição dos fatores de qualidade ambiental a partir da declaração ou revelação das preferências com base nas opiniões dos usuários torna-se necessária.

Nesse contexto estratégico, a investigação empírica desta pesquisa, partindo da formulação de uma sentença mapeadora geral, instrumento básico da Teoria das Facetas, foi desenhada e tomou para estudo duas características dos elementos de escritórios de coworking, complexidade e coerência, pelas suas prováveis influências na qualidade visual percebida.

Este artigo objetiva, então, prover informações empíricas sobre o efeito da complexidade e da coerência de escritórios de coworking na qualidade visual percebida. De modo específico, busca examinar o efeito da complexidade e da coerência de escritórios de coworking na agradabilidade e na empolgação que esses espaços transmitem, sendo essas dimensões avaliativas utilizadas aqui como uma expressão da qualidade visual percebida nesses locais, na medida em que, presumivelmente, escritórios de coworking agradáveis e empolgantes são preferidos em relação a outros desagradáveis e sombrios.

Apesar das respostas avaliativas, por si só, não poderem prever o comportamento real, a avaliação combinada de respostas avaliativas e do comportamento previsto dá uma boa indicação do comportamento real (NASAR, 1988). Dessa forma, na presente pesquisa, os respondentes foram convidados a indicar em que medida várias cenas de escritórios de coworking favoreciam: (i) o prazer de trabalhar naquele local; (2) a empolgação percebida.

Essa abordagem se justifica para a área da ergonomia do ambiente construído por favorecer a adequabilidade dos projetos de escritórios de coworking às necessidades psicológicas de seus trabalhadores/usuários, já que, conforme Nasar (2000), pesquisas apontam que as características dos elementos de um ambiente têm importantes impactos na experiência humana, podendo evocar fortes emoções como agrado ou desagrado, atuar como efeito empolgante ou triste e possibilitar deduções sobre os lugares e as pessoas. Podem, ainda, influenciar o comportamento humano, de modo que as pessoas estão mais propensas a frequentar ambientes percebidos favoravelmente e evitar outros que julgam negativos. 


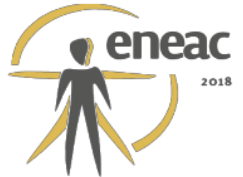

\section{CONSIDERAÇÕES TEÓRICAS}

As novas formas de trabalho apontam para referências altamente móveis e nômades, variados e/ou com alta densidade de uso do espaço, com uso compartilhado e temporário de múltiplos ambientes, ambientes baseados na diversidade de tarefas, períodos prolongados e irregulares de trabalho (LAING, 2006). Nesse aspecto, os escritórios de coworking refletem os novos padrões de espaços de trabalho.

O coworking é definido como um escritório compartilhado por diversos profissionais de diferentes empresas e ramos empresariais, que dividem não apenas os custos, mas compartilham o mesmo espaço físico, conversando, trocando experiências e aumentando seu networking (PINHEIRO, 2014; CAPDEVILA, 2015). Spinuzzi (2012) relata que seu maior diferencial em relação a outros escritórios compartilhados é o foco na comunidade e sua dinâmica de compartilhamento de conhecimento.

Ainda há poucas pesquisas publicadas sobre a contribuição da ergonomia nesses espaços, certamente pelo fato de ser uma ideia recente, criada em 1999, por Bernie DeKoven, com o primeiro coworking fundado apenas em 2005, o Muse Espiral, em São Francisco.

Chegado ao Brasil no ano de 2007, em 2017, o país já contava com 810 espaços ativos de escritórios coworking. Com número sempre crescente, hoje, estão presentes em todas as regiões do país, movimentando cerca de 82 milhões de reais ao ano, segundo divulgado no Censo Coworking Brasil, a partir dos dados coletados numa pesquisa realizada pela Movebla e Ekonomio, em parceria com a Coworking Brasil e com apoio do Seats2meet.

De acordo com o Censo Coworking 2016, através de pesquisa realizada anualmente com o objetivo de entender e analisar o mercado desse tipo de escritório no Brasil, os coworkers advém das mais diversas áreas de conhecimento. Quanto à faixa etária desses usuários, ainda segundo dados da mesma pesquisa, a maioria tem entre 20 e 40 anos. Para Medeiros (2016), esses são considerados "millenials", ou geração $\mathrm{Y}$, que, em sua maioria, estão entre as faixas etárias de pessoas que nasceram nas décadas de 1980 - 90 e, muitas vezes, são recém-formados, grupos que estão montando sua própria empresa, profissionais liberais e freelancers que possuem horários flexíveis para o trabalho.

A ergonomia, como a tecnologia "projetual" das comunicações entre humanos e máquinas, trabalho e ambiente (MORAES; MONT'ALVÃO, 2000), está interessada em contribuir com pesquisas sobre novas formas de pensar o projeto do ambiente de trabalho, esforçando-se para que bons resultados relacionados a esse trinômio sejam obtidos.

Com esse propósito em mente, é importante criar bases objetivas para decisões de projeto para espaços de coworking e, a partir deste ponto, este artigo trará alguns postulados teóricos que embasam a preferência ambiental e sua avaliação, com o propósito principal de apoiar as discussões dos resultados empíricos desta pesquisa.

Há, portanto, de se iniciar ressaltando que Kaplan (1988) define o julgamento ambiental como produto de dois processos relacionados com a sobrevivência humana: "envolvimento" e "fazer sentido", para o autor um ambiente deve ser envolvente para atrair a atenção e fazer sentido para que se possa operar nele. A complexidade e a coerência são características ambientais relevantes nesses dois processos.

A complexidade envolve a "diversidade" dos elementos na cena, ou seja, o número de diferentes elementos visíveis e a distinção entre eles. Pouca complexidade é monótona, muita é estressante, o nível intermediário é, presumivelmente, mais prazeroso (BERLYNE,1972; WOHLWILL, 1976). Logo, segundo Nasar (2000), o tom hedônico da cena, em relação à complexidade, tem a forma de "U" invertido.

A coerência é definida como o grau em que a cena se encaixa, incluindo fatores que facilitam a organização do plano da imagem, sua compreensão e estruturação, podendo reduzir a 


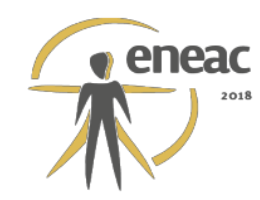

incerteza e aumentar o tom hedônico (beleza ou agradabilidade). Auxiliando a compreensão, a coerência (alcançada através da redução do contraste entre os elementos da cena) pode reduzir a incerteza e aumentar o tom hedônico (KAPLAN, 1988).

Apesar da qualidade visual percebida depender, em parte, de fatores perceptuais/cognitivos, ela é, por definição, um julgamento emocional que envolve avaliação e sentimentos (NASAR, 1988). Como resultado, a qualidade visual percebida é medida aqui através de julgamentos avaliativos para várias cenas de escritórios de coworking.

Para serem relevantes, tais julgamentos devem focar nas dimensões avaliativas que as pessoas realmente usam para julgar o ambiente. Ward e Russel (1981) encontraram quatro aspectos notáveis da avaliação ambiental, quais sejam: agradável, estimulante, empolgante, calmante. A agradabilidade é uma dimensão puramente avaliativa, a dimensão estimulante é independente da dimensão avaliativa. As dimensões empolgante e calmante envolvem misturas de avaliação e estímulo. As pessoas experienciam lugares empolgantes como mais agradáveis e estimulantes que os tristes. Elas experienciam lugares calmantes como mais agradáveis e menos estimulantes do que aqueles aflitivos.

Em relação aos efeitos da complexidade nas respostas avaliativas para o ambiente, é postulado que a agradabilidade é significativamente maior para cenas com moderada complexidade do que para aquelas com complexidade baixa ou alta. A empolgação é maior para as cenas com complexidade alta, moderada para as cenas com complexidade média e menor para as cenas com complexidade baixa (NASAR, 2008).

Em relação aos efeitos da coerência (obtida através da redução do contraste entre os elementos da cena) nas respostas avaliativas para o ambiente, é postulado que a agradabilidade é maior para cenas com coerência alta (contraste baixo), moderada para cenas com coerência média (contraste médio) e menor para as cenas com coerência baixa (contraste alto). A empolgação é baixa para as cenas com coerência alta (contraste baixo), moderada para as cenas com coerência média (contraste médio) e maior para as cenas com coerência baixa (contraste alto) (NASAR, 2008).

A qualidade visual percebida, segundo Galvez e Costa Filho (2016), tem efeitos poderosos sobre a experiência do usuário na compreensão do espaço e, consequentemente, na sua capacidade de processar a informação e avaliar o ambiente.

\section{CONSIDERAÇÕES METODOLÓGICAS}

Nesta pesquisa, formulou-se uma sentença mapeadora geral (general mapping sentence), instrumento básico da Teoria das Facetas, para auxiliar na estruturação da investigação empírica. Essa sentença, segundo Costa Filho et al. (2016), destaca as facetas e resulta em uma frase norteadora para o desenho do instrumento de coleta de dados. Como tal, reflete a hipótese sobre as relações entre os elementos internos das facetas, sendo precisamente essas relações que serão testadas na situação empírica.

O Quadro 1 apresenta a sentença mapeadora geral para a avaliação da qualidade visual percebida em escritórios de coworking, com três tipos de facetas. O primeiro tipo se refere ao grupo pesquisado. O segundo tipo diz respeito ao conteúdo das variáveis pesquisadas. Juntas, essas duas facetas determinam o campo de interesse da pesquisa. $O$ terceiro tipo equivale ao universo de respostas, apresentada como numa escala ordenada de aceitação.

A partir da sentença mapeadora geral (Quadro 1), os elementos das facetas de conteúdo (complexidade e contraste) podem ser organizados de forma semelhante a uma análise combinatória, produzindo nove diferentes conjuntos ( $\mathrm{A} 3 \times \mathrm{B} 3=\mathrm{AB} 9)$, que transmitem uma relação ou situação específica. A seta indica o mapeamento do conteúdo no conjunto de 
possibilidades de respostas, ou seja, cada uma dessas situações específicas compartilha de um racional, que apresenta a variedade de cinco respostas possíveis.

O conjunto de nove cenas, utilizadas como elementos de estímulo no questionário online, está diretamente relacionado às variáveis desta pesquisa, listadas na sentença mapeadora geral para a avaliação da qualidade visual percebida em escritórios de coworking, todas selecionadas no "Google Imagem", levando em conta duas características dos elementos desse tipo de espaço complexidade e coerência - em três diferentes níveis (baixo, médio, alto) (Quadro 2).

\section{Quadro 1 - Sentença mapeadora geral para a avaliação da qualidade visual percebida em escritórios de coworking.}

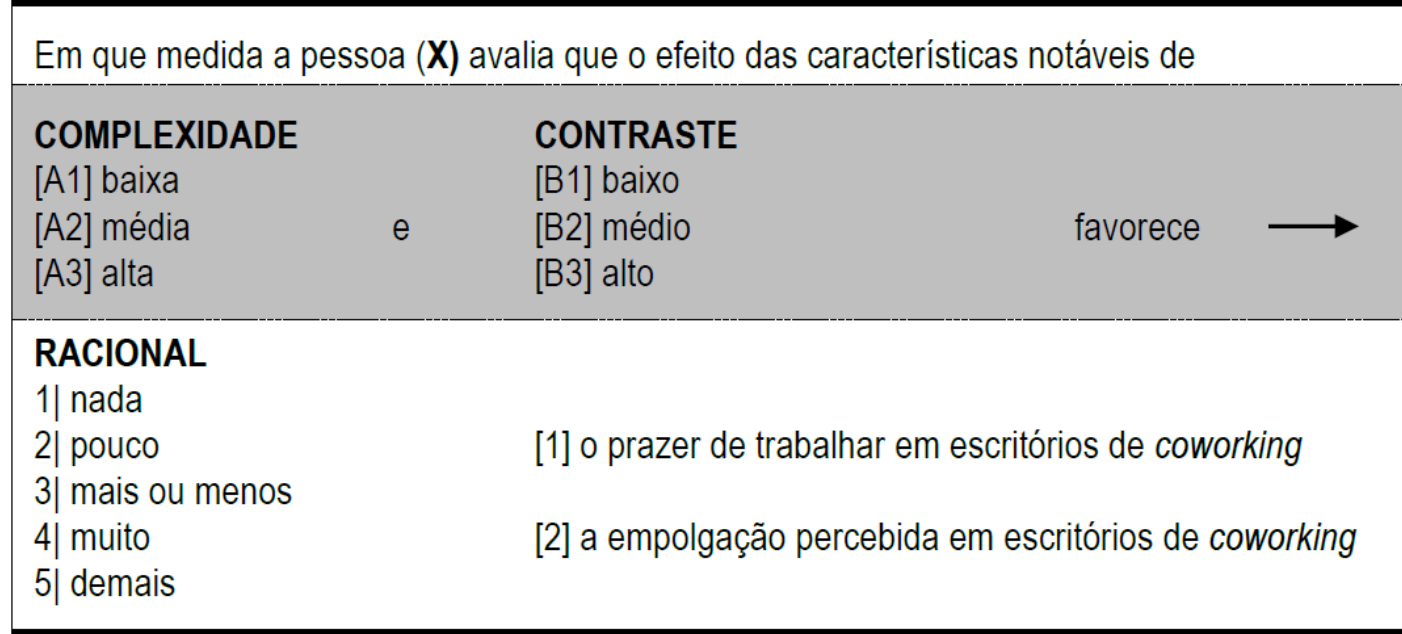

Fonte: Autores da pesquisa.

A sentença mapeadora geral, como uma hipótese inicial da pesquisa, será analisada em relação aos resultados empíricos que devem confirmar ou contestar essa estrutura. Logo, após a interpretação dos dados e na fase final, há informações suficientes para construir ou não uma nova sentença mapeadora geral como consequência direta dos resultados empíricos encontrados (COSTA FILHO, 2014).

A investigação empírica contou com um questionário online, criado por meio da ferramenta "Formulário Google", para coletar os dados. O questionário gerado, baseado no Sistema de Classificações Múltiplas - que consiste em solicitar aos participantes para classificar os mesmos elementos diversas vezes, com a finalidade de compreender suas ideias sobre o objeto de estudo -, foi divulgado através de redes sociais. A escolha dessa ferramenta se deu pela conveniência de ser um meio em que se conseguiria maior número de respondentes; não depender totalmente de verbalizações e permitir o uso de imagens.

Com relação aos procedimentos de pesquisa, inicialmente era informado aos respondentes que: (i) o estudo focava na avaliação visual de escritórios de coworking; (ii) não havia resposta certa ou errada; (iii) se garantia sigilo e anonimato. Em seguida, era pedido que o participante - após se identificar por sexo, idade, escolaridade - indicassem em que medida cada cena de escritórios de coworking favorecia: (i) o prazer de trabalhar naquele local; (ii) a empolgação percebida no local. Como universo de respostas, foi ofertado cinco diferentes valores, que iam de "nada" (mínimo favorecimento) até "demais" (máximo favorecimento), passando pela opção "mais ou menos" (intermediário favorecimento).

No total, depois que a pesquisa foi encerrada, contou-se com a participação de 77 pessoas, sendo a maioria delas formada por mulheres $(57,1 \%)$, entre 19 a 30 anos de idade $(50,6 \%)$ com nível de escolaridade superior completo $(66,7 \%)$. 


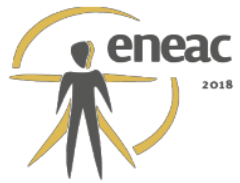

Quadro 2 - Escritórios de coworking representando as relações de complexidade e de contraste.

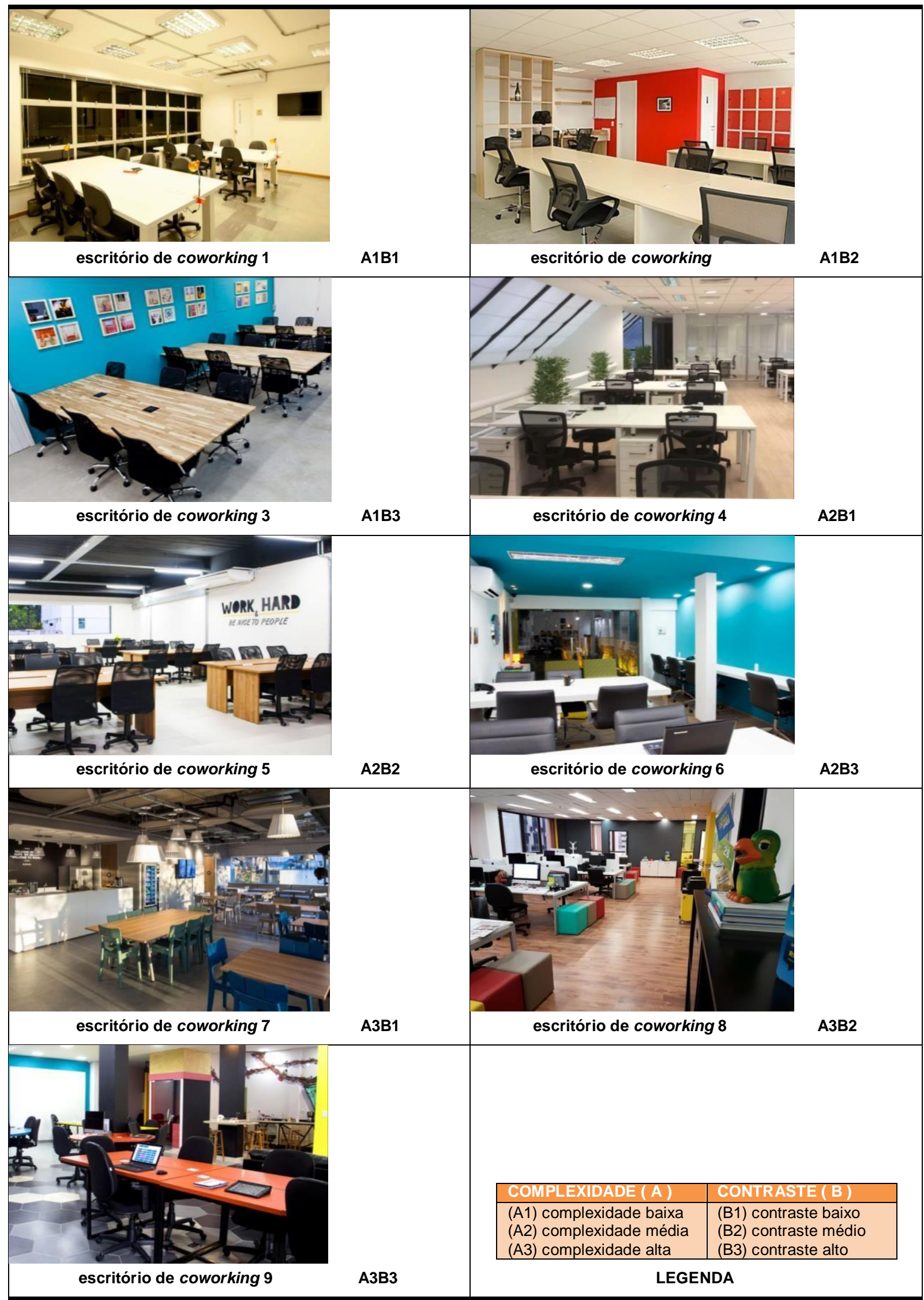

Fonte: Google Imagens. 


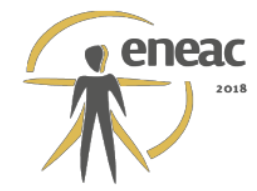

O tratamento dos dados iniciou-se com a tabulação e a posterior análise comparativa da distribuição das frequências (MARCONI; LAKATOS, 2003), buscando: (i) analisar comparativamente a distribuição das frequências em relação aos três níveis de complexidade e coerência; (ii) identificar as cenas mais e menos relacionadas com as respostas avaliativas para a agradabilidade e a empolgação percebidas; (iii) coligar tais resultados empíricos a um determinado nível de complexidade e de coerência percebidas.

\section{CONSIDERAÇÕES EMPÍRICAS}

A partir da análise comparativa da tabela de distribuição das frequências - para os cinco diferentes níveis propostos de respostas avaliativas para a agradabilidade e a empolgação percebidas nas nove cenas de escritórios de coworking -, a hipótese inicial da pesquisa sobre as relações entre os elementos internos das facetas, expressa na sentença mapeadora geral formulada, foi testada.

Ao explorar os dados empíricos, a partir das duas tabelas de distribuição das frequências elaboradas, pôde-se verificar o efeito da complexidade e da coerência dos escritórios de coworking na qualidade visual percebida, ou seja, o efeito dessas duas características dos elementos desse tipo de escritório na agradabilidade e na empolgação percebidas.

A Tabela 1 mostra a distribuição das frequências para os cinco diferentes níveis propostos de respostas avaliativas para a AGRADABILIDADE nas nove cenas de escritórios de coworking, percebidas pelos 77 sujeitos participantes.

Tabela 01 - Níveis de agradabilidade percebidos nas nove cenas de escritórios de coworking.

\begin{tabular}{|c|c|c|c|c|c|c|c|c|c|}
\hline & A1B1 & A1B2 & A1B3 & A2B1 & A2B2 & A2B3 & A3B1 & A3B2 & A3B3 \\
\hline NADA & $5,2 \%$ & $5,2 \%$ & $5,2 \%$ & $10,4 \%$ & $0 \%$ & $2,6 \%$ & $19,5 \%$ & $9,1 \%$ & $7,8 \%$ \\
\hline POUCO & $23,4 \%$ & $13 \%$ & $3,9 \%$ & $27,3 \%$ & $14,3 \%$ & $10,4 \%$ & $19,5 \%$ & $13 \%$ & $14,3 \%$ \\
\hline MAIS OU MENOS & $28,6 \%$ & $28,6 \%$ & $29,9 \%$ & $31,2 \%$ & $33,8 \%$ & $16,9 \%$ & $26 \%$ & $32,5 \%$ & $23,4 \%$ \\
\hline MUITO & $23,4 \%$ & $22,1 \%$ & $44,2 \%$ & $20,8 \%$ & $26 \%$ & $50,6 \%$ & $27,3 \%$ & $29,9 \%$ & $40,3 \%$ \\
\hline DEMAIS & $19,5 \%$ & $31,2 \%$ & $16,9 \%$ & $10,4 \%$ & $26 \%$ & $19,5 \%$ & $7,8 \%$ & $15,6 \%$ & $14,3 \%$ \\
\hline TOTAL & $100 \%$ & $100 \%$ & $100 \%$ & $100 \%$ & $100 \%$ & $100 \%$ & $100 \%$ & $100 \%$ & $100 \%$ \\
\hline
\end{tabular}

Fonte: autores da pesquisa com base nos resultados.

Em geral, os resultados omitem o efeito esperado da complexidade e da coerência nas respostas avaliativas para a agradabilidade. Considerando, primeiramente, os resultados para a complexidade, conforme mostra a Tabela 1, a agradabilidade, comparativamente, é mais alta para escritórios de coworking menos complexos, reduz para os moderadamente complexos, sendo menor para os mais complexos.

Considerando, agora, os resultados para o contraste, conforme mostra a Tabela 1 e também de modo integrado, a agradabilidade é menor para escritórios de coworking com alta coerência (contraste baixo), mais alta para aqueles com média coerência (contraste médio) e reduz para os escritórios de coworking com baixa coerência (contraste alto).

De modo pontual, os resultados também omitem o efeito esperado da complexidade e da coerência nas respostas avaliativas para a agradabilidade. A cena de número 2 (Figura 1a), 


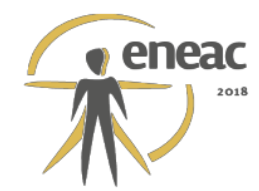

escritório de coworking menos complexo e com média coerência (contraste médio), como mostra a Tabela 1, foi percebida pelos respondentes como mais agradável, portanto com qualidade visual percebida e, nesse caso, altamente agradável.

Quanto ao nível de complexidade mínima da cena de número 2, conforme referenciado, distancia-se da complexidade ideal de estímulo, aumentando a monotonia. Pelo viés teórico, a agradabilidade é significantemente aumentada com a complexidade média, uma vez que a complexidade mínima é postulada como monótona e entediante, enquanto a alta é caótica e estressante. Tal resultado empírico destoa dos postulados teóricos para a agradabilidade.

Cabe destacar que a característica de alta coerência (contraste baixo) da cena de número 2 , conforme referenciado, ao facilitar a compreensão, favorece a coerência que ainda reduz a incerteza e aumenta o tom hedônico (agradabilidade). Esse resultado para a agradabilidade destoa dos postulados teóricos.

Inversamente, a cena de número 7 (Figura 1b), escritório de coworking com complexidade e coerência alta (contraste baixo), conforme Tabela 1, foi percebida pelos respondentes como a menos agradável, portanto com menor qualidade visual percebida e, assim, desagradável. Tais achados omitem o efeito esperado de complexidade (moderado) e revela o efeito de alta coerência (contraste baixo) nas respostas avaliativas para a agradabilidade.

Figura 1 - A agradabilidade percebida nas cenas de escritórios de coworking.

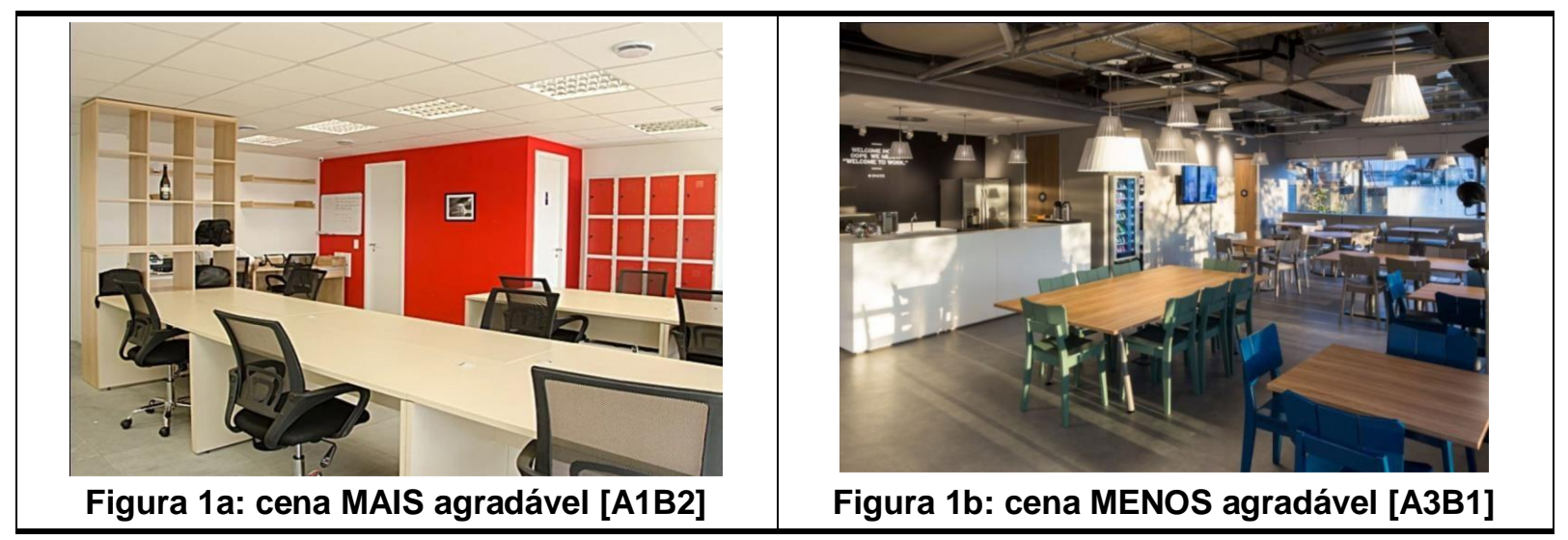

Fonte: Google Imagens.

A Tabela 2 (próxima página) mostra a distribuição das frequências para os cinco diferentes níveis propostos de respostas avaliativas para a EMPOLGAÇÃO nas nove cenas de escritórios de coworking, percebidas pelos 77 sujeitos participantes.

Em geral, os resultados revelam o efeito esperado da complexidade e da coerência nas respostas avaliativas para a empolgação percebida. Focando, primeiramente, nos resultados para a complexidade, conforme Tabela 2, a empolgação percebida, de modo integrado, é mais alta para escritórios de coworking mais complexos, reduz para os moderadamente complexos, sendo menor para aqueles menos complexos.

Focando, agora, nos resultados para a coerência, conforme Tabela 2, a empolgação percebida, de modo integrado, é menor para escritórios de coworking com alta coerência (contraste baixo), aumenta para aqueles com média coerência (contraste médio), sendo mais alta para os escritórios de coworking com baixa coerência (contraste alto). 
Tabela 2 - Níveis de empolgação percebidos nas nove cenas de escritórios de coworking

\begin{tabular}{|c|c|c|c|c|c|c|c|c|c|}
\hline & A1B1 & A1B2 & A1B3 & A2B1 & $\mathrm{A} 2 \mathrm{~B} 2$ & A2B3 & A3B1 & A3B2 & A3B3 \\
\hline NADA & $21,1 \%$ & $7,9 \%$ & $5,3 \%$ & $18,4 \%$ & $10,5 \%$ & $5,3 \%$ & $18,4 \%$ & $9,2 \%$ & $5,3 \%$ \\
\hline POUCO & $23,7 \%$ & $21,1 \%$ & $11,8 \%$ & $25 \%$ & $23,7 \%$ & $21,1 \%$ & $17,1 \%$ & $7,9 \%$ & $7,9 \%$ \\
\hline MAIS OU MENOS & $22,4 \%$ & $15,8 \%$ & $31,6 \%$ & $27,6 \%$ & $28,9 \%$ & $28,9 \%$ & $22,4 \%$ & $9,2 \%$ & $23,7 \%$ \\
\hline MUITO & $21,1 \%$ & $21,1 \%$ & $34,2 \%$ & $19,7 \%$ & $26,3 \%$ & $34,2 \%$ & $27,6 \%$ & $38,2 \%$ & $35,5 \%$ \\
\hline DEMAIS & $11,8 \%$ & $34,2 \%$ & $17,1 \%$ & $9,2 \%$ & $10,5 \%$ & $10,5 \%$ & $14,5 \%$ & $35,5 \%$ & $27,6 \%$ \\
\hline TOTAL & $100 \%$ & $100 \%$ & $100 \%$ & $100 \%$ & $100 \%$ & $100 \%$ & $100 \%$ & $100 \%$ & $100 \%$ \\
\hline
\end{tabular}

Fonte: Autores da pesquisa com base nos resultados.

De modo pontual, os resultados revelam o efeito esperado da complexidade e da coerência nas respostas avaliativas para a empolgação percebida nas cenas de escritórios de coworking. A cena de número 8 (Figura 2), escritório de coworking mais complexo e com média coerência (contraste médio) foi percebida pelos respondentes como mais empolgante (Tabela 2), portanto com qualidade visual percebida e, nesse caso, altamente empolgante.

Figura 2: O maior nível de empolgação percebido nas cenas de escritórios de coworking.

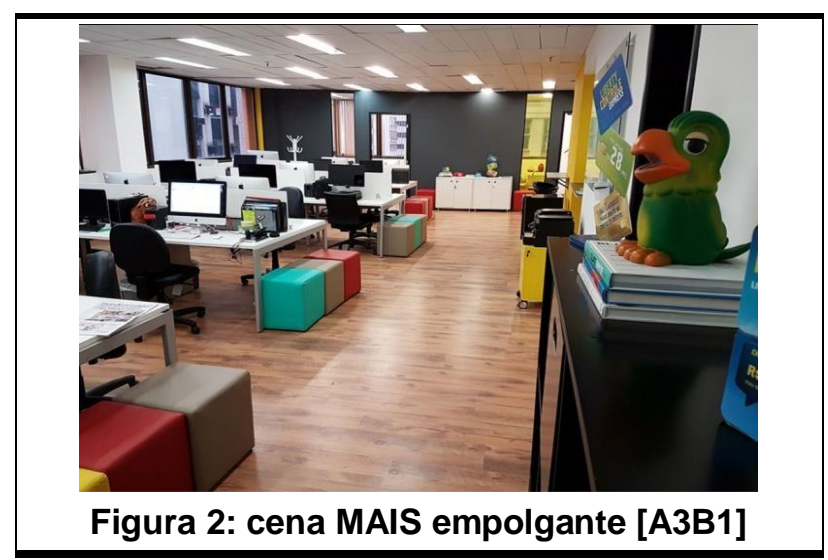

Fonte: Google Imagens.

Quanto ao nível de complexidade máxima da cena de número 8, conforme exposto nas considerações teóricas, é considerado o nível ideal de estímulo da complexidade, aumentando a empolgação percebida. Pela perspectiva teórica, a empolgação é alta para a complexidade alta. Tal resultado mostrou-se consistente com os postulados teóricos.

Há de se ressaltar que contraste médio da cena de número 8 , conforme referenciado nas considerações teóricas apresentadas, favorece apenas moderadamente a coerência, que deveria ser alta para aumentar a empolgação percebida. Esse achado para a empolgação, contudo, destoa do postulado teórico.

Inversamente, a cena de número 4 (Figura 3a), escritório de coworking com complexidade moderada e com baixa coerência (contraste alto), conforme a Tabela 2, foi percebida pelos respondentes como aquela menos empolgante e, por isso, altamente triste/sombria. Do mesmo modo, com igual resposta avaliativa, a cena de número 7 (Figura 3b), escritório de coworking com complexidade alta e com alta coerência (contraste baixo), como mostra a Tabela 2, foi 
percebida como igualmente menos empolgante e, nesse sentido, também altamente triste/sombria. Os achados para a primeira cena (4) omitem o efeito esperado de complexidade alta e alta coerência (contraste baixo) nas respostas avaliativas para a agradabilidade. Já os achados para a segunda cena (7), inversamente, revelam o efeito, embora tenha sido escolhida como menos empolgante, sugerindo a consideração de outras características dos elementos de escritório de coworking nesse tipo de avaliação.

Figura 3 - Os menores níveis de empolgações percebidos nas cenas de escritório de coworking.

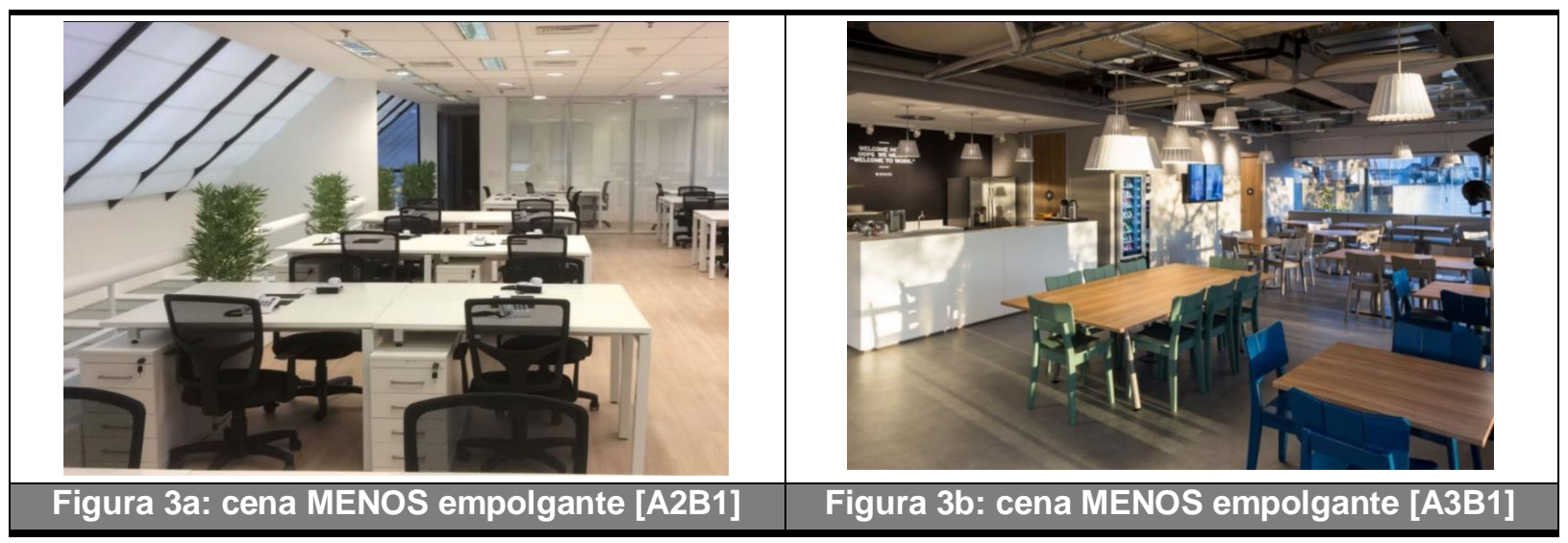

Fonte: Google Imagens.

\section{CONCLUSÃO}

A medição da imagem avaliativa em escritórios de coworking tem importância por criar uma base objetiva para decisões sobre a qualidade visual percebida nesses espaços, aqui privilegiando as respostas avaliativas para a agradabilidade e a empolgação percebidas.

Considerando os resultados integrados para as cenas utilizadas na investigação empírica desta pesquisa, que teve como objetivo prover informações empíricas sobre o efeito da complexidade e da coerência em escritórios de coworking, apurou-se que eles: (i) omitem o efeito esperado da complexidade média e da coerência alta (contraste baixo) nas respostas avaliativas para a agradabilidade percebida em ambientes, pois revelam que a agradabilidade seria elevada através da complexidade média e da coerência alta (contraste baixo) nas cenas dos escritórios de coworking; (ii) revelam o efeito esperado da complexidade alta e da coerência baixa (contraste alto) nas respostas avaliativas para a empolgação percebida em ambientes, ou seja, confirmam o postulado teórico para escritórios de coworking.

Considerando, agora, os resultados de maneira específica para as cenas que obtiveram as melhores respostas avaliativas para a agradabilidade e para a empolgação percebidas nas cenas dos escritórios de coworking, conclui-se que: (i) o efeito da complexidade baixa e da coerência média (contraste médio) eleva a agradabilidade percebida; (ii) o efeito da complexidade alta e coerência média (contraste alto) eleva a empolgação percebida.

Num sentido inversos, conclui-se, ainda, que a complexidade alta reduz a agradabilidade em escritórios de coworking, assim como a complexidade média e o contraste baixo (alta coerência) reduz a empolgação percebida nesses mesmos espaços de trabalho. 


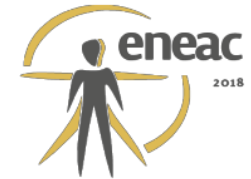

\section{REFERÊNCIAS}

BERLYNE, D. E. Ends and meanings of experimental aesthetics. Canadian Journal of Psychology, 26, 1972. p 303-325.

CAPDEVILA, I. Co-working spaces and the localised dynamics of innovation in Barcelona. International Journal of Innovation Management. Vol. 19, N. 3. 2015. 28 p.

COSTA FILHO, L. L.; OLIVEIRA, I. F.; YOKOYAMA, S. A. A qualidade percebida da paisagem midiática do comércio varejista de Caruaru. In: MONT'ALVÃO, C.; VILLAROUCO, V. (Orgs.), Um novo olhar para o projeto: 3: a ergonomia do ambiente construído. Recife: Editora UFPE, 2016.

COSTA FILHO, L. L. O enfoque da Teoria das Facetas na avaliação de lugares. In: MONT'ALVÃO, C.; VILLAROUCO, V. (Orgs.), Um novo olhar para o projeto, 2: a ergonomia no ambiente construído. Recife: Ed. UFPE, 2014, p. 11-26.

GALVEZ, C., COSTA FILHO, L. Complexidade da sinalização e qualidade percebida. In: V ENEAC ENCONTRO NACIONAL DE ERGONOMIA DO AMBIENTE CONSTRUÍDO E VI SEMINÁRIO NACIONAL DE ACESSIBILIDADE INTEGRAL, 2016. Recife. Anais... Recife, UFPE, 2016.

KAPLAN, Stephen. Perception and landscape: conceptions and misconceptions. In: NASAR, J. L. (Ed.). Environmental aesthetics: theory, research, and application. New York: Cambridge University Press, 1988. p. $45-55$.

LAING, A. New patterns of work: the design of the office. In: WORTHINGTON, J. (Ed.). Reinventing the workspace. 2nd. ed. Oxford: Architectural Press / Elsevier, 2006.

MARCONI, M. A.; LAKATOS, E. M.; Fundamentos de metodologia científica. 5. ed. São Paulo: Atlas, 2003.

MEDEIROS, C. S. Ribeira Hub, galerias e coworking: requalificação arquitetônica do edifício Presidente Café Filho / Cleyton Santos de Medeiros. 2016. Dissertação (Mestrado) - Programa de Pós-Graduação em Arquitetura e Urbanismo, UFN, Natal, 2016.

MORAES, A; MONT'ALVÃO, C. Ergonomia: conceitos e aplicações. 4. ed. ampliada. Rio de Janeiro: 2AB, 2009.

NASAR, J. L. Visual quality by design. Michigan: Haworth, Inc., 2008.

The evaluative image of places. In WALSH, W. B.; CRAIK, K. H.; PRINCE, R. H. 2nd. ed. (Eds.). Person-environment psychology: new directions and perspectives. New Jersey: Lawrence Erlbaum Associates, 2000. p. 117-168.

The effect of sign complexity and coherence on the perceived quality of retail scenes. In NASAR, J. L. (Ed.). Environmental Aesthetics: theory, research, \& applications. New York: Cambridge University Press, 1988. p. 300-320.

PINHEIRO, P. S. QG espaço de coworking: o espaço de trabalho contemporâneo e a influência do conceito colaborativo. 2014. 81 f. Trabalho de Conclusão de Curso (Graduação em Arquitetura e Urbanismo) - Curso Arquitetura e Urbanismo. UFN, Natal, 2014.

REIS, T. C. dos; MORAES, A. Contribuição da ergonomia em projeto de espaço de trabalho. In MORAES, A. (Org.). Ergodesign do ambiente construído e habitado: ambiente urbano, ambiente público, ambiente laboral. Rio de Janeiro: iUsEr, 2004.

SPINUZZI, C. Working alone together: coworking as emergent collaborative activity. Journal of Business and Technical Communication, 26(4), 2012, 399-441. 


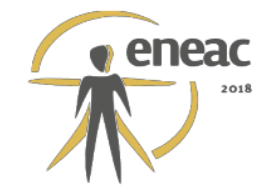

VAN DER LINDER, J. Ergonomia e design: prazer, conforto e risco no uso dos produtos. Porto Alegre: UniRitter Ed., 2007.

WARD, L.; RUSSEL, J. Cognitive set and the perception of place. Environment and Behaviour, v. 13, n. 5, 1981. p. 219-235.

WOHWILL, J. F. Environmental aesthetics: The environment as a source of affect. In: ALTMANN, I.; WOHWILL, J. F. (Eds.), Human Behaviour and Environment, V. 1, 1976. p 37-86. 